\title{
Representations of British Chinese identities and British television drama: mapping the field
}

Article

Accepted Version

Knox, S. (2019) Representations of British Chinese identities and British television drama: mapping the field. Journal of British Cinema and Television, 16 (2). pp. 125-145. ISSN 1755-1714 doi: https://doi.org/10.3366/jbctv.2019.0465 Available at https://centaur.reading.ac.uk/78894/

It is advisable to refer to the publisher's version if you intend to cite from the work. See Guidance on citing.

To link to this article DOI: http://dx.doi.org/10.3366/jbctv.2019.0465

Publisher: Edinburgh University Press

All outputs in CentAUR are protected by Intellectual Property Rights law, including copyright law. Copyright and IPR is retained by the creators or other copyright holders. Terms and conditions for use of this material are defined in the End User Agreement.

www.reading.ac.uk/centaur 
Central Archive at the University of Reading

Reading's research outputs online 


\title{
Representations of British Chinese Identities and British Television Drama: Mapping the Field
}

\begin{abstract}
:
While important scholarship exists on the television representations of Asian American identities, research in the UK has been focused on African Caribbean and South Asian identities. Very little scholarly attention has been paid to televisual representations of British Chinese identities, despite the British Chinese constituting one of the larger and fastest growing ethnic minority groups within contemporary Britain.
\end{abstract}

Informed by an understanding of the complexity of the term 'British Chinese', this article explores the representation of British Chinese identities in British television drama. Despite the long-standing absence and invisibility of such identities in British television, as perceived within the popular imagination in Britain and British Chinese discourses, the article finds that a larger number of British Chinese actors have found notable employment in British television than is commonly acknowledged or remembered within the popular imagination.

The article draws on a database that deploys a range of research, including archive research at the BFI Reuben Library, to map the presence of British Chinese actors in British television drama since 1945 . Through this historiographic focus, the article identifies some of the most significant trends in representations of British Chinese identities in British television drama. It then illustrates and provides more specific texture to these broader patterns through the close textual analysis of a case study, the BBC1 flagship series Sherlock (2010-present). It concludes by reflecting on the contemporary period, which has seen an influx of British Chinese actors in British television drama as well as high-profile diversity campaigning within Britain.

Keywords:

BAME representations; politics of representation; yellow peril; Orientalism; Sherlock; BBC; Burt Kwouk; David Yip; Sarah Lam; Gemma Chan. 


\section{Representations of British Chinese Identities and British Television Drama: Mapping the Field}

This article is concerned to map out how representations of British Chinese identities 'function as cultural sites for the articulation of specific meanings, relations, histories and struggles' (Gray 2000: 125) within the history of British television drama. A body of academic research has been conducted in the UK and the USA on media representations of ethnic minorities, and this article builds on this valuable work. However, while important scholarship exists on the television representations of Asian American identities (e.g. Hamamoto 1994, Kim 2004, Ono and Pham 2009, Yuen 2017), research in the UK has been focused on African Caribbean and South Asian identities (e.g. Malik 2001, Malik and Newton 2017). Very little scholarly attention has been paid to televisual representations of British East Asian identities more broadly and British Chinese identities more specifically. With television continuing to be a key site for the production and negotiation of ideologies, identities and socio-cultural frameworks of meaning (Hall 1995), and to be linked in Britain to notions of public service broadcasting, it seems timely to begin to redress this gap and give long overdue consideration to television representations of British Chinese identities.

This gap is connected to the long-standing absence and invisibility of British Chinese identities in British television, as perceived within both the popular imagination in Britain and (more explicitly so) British Chinese discourses. ${ }^{1}$ Indeed, The Chinese Detective (BBC1 1981-1982) remains the only British primetime series to feature a British Chinese actor as the singular lead, and children's series Spirit 
Warriors (CBBC 2010) was the first British drama series with a predominantly British East Asian cast. ${ }^{2}$ This is linked to the broader general invisibility of British Chinese identities in dominant cultural discourses within the UK. This absence within the popular imagination is especially notable given the long-standing socio-historical presence of the British Chinese within British society (Benton and Gomez 2008) and that they constitute one of the larger and fastest growing ethnic minority groups within contemporary Britain (ONS 2009).

What is more, as this article will explore, there has been a long-standing British Chinese presence within British television drama. This presence shows that the perception of the long-standing absence of British Chinese identities is partially implicated in (intentional or not) processes of overlooking, forgetting and marginalising, certainly within dominant cultural discourses within Britain. Given the self-perpetuating quality of discursive marginalisation, there is need for critical intervention to raise the profile of this representational presence within scholarship and the popular imagination, and encourage reflection on it, so that there can be more sustained engagement with this noteworthy aspect of Britain's televisual cultural heritage.

To help begin this process, this article will identify some of the most significant patterns in representations of British Chinese identities in British television drama, and then illustrate these dominant trends through a case study of the BBC1 flagship series Sherlock (2010-present). To do both is important, as the historiographic engagement with broader patterns helps to move current debates 
(where they exist) beyond the level of the anecdotal, and the close textual analysis productively offers nuance and concrete specificity. My discussion will be informed by an understanding of the complexity of British Chinese identity, drawing on the seminal work of such scholars as Rey Chow and len Ang, who have argued against understanding 'Chineseness' as pre-given, homogeneous and fixed. ${ }^{3}$ Chow has called for 'Chineseness [to] be productively put under erasure - not in the sense of being written out of existence but in the sense of being unpacked' (1998: 24). Providing an illuminating contribution to this anti-essentialist impulse, Ang has argued that:

Chineseness is not a category with a fixed content - be it racial, cultural or geographical - but operates as an open and indeterminate signifier whose meanings are constantly renegotiated and rearticulated in different sections of the Chinese diaspora. [...] There are, in this paradigm, many different Chinese identities, not one. This proposition entails a criticism of Chinese essentialism, a departure from the mode of demarcating Chineseness through an absolutist oppositioning of authentic and inauthentic, pure and impure, real and fake. (2001: 38)

In its marked hybridity, the term 'British Chinese' opens up space for multiple lines of coexistence, contradiction and cross-connection and, to draw on Homi Bhabha's thoughts, usefully 'denies the essentialism of a prior given original or originary culture, [and so] we see that all forms of culture are continually in the process of hybridity.' (cited in Rutherford 1990: 211) Gregor Benton and Edmund Gomez (2008) have argued that, whilst British Chinese culture has long been perceived from without as homogenous, it is, inevitably, anything but, with 
significant differences of regional, ethnic, class, linguistic and generational allegiances and divisions. The 2011 'Contesting "British Chinese" Culture: Forms, Histories, Identities' conference organised by Ashley Thorpe and Diana Yeh considered British Chineseness as not a self-evident identity, but a contested political construction that may be mobilised differently according to context.

My discussion will further draw on an extensive database I have collated that maps the presence of British Chinese actors in British television drama since 1945. Striving for, but inevitably never achieving comprehensiveness, this database draws on information gathered from archive research at the BFI Reuben Library, online resources such as the Internet Movie Database, the BFI's Screenonline database, the BBC Genome Project and several British Chinese online forums and blogs (e.g. www.britishchineseonline.com, http://bbczeitgeist.blogspot.co.uk), as well as newspapers and trade publications. It is informed by an understanding that the very on-screen presence of British Chinese actors, their appearance in British Chinese and/or Chinese roles, and instances of cross-casting, all have meaningful importance to representations of British Chinese identities.

Of course, the actors of interest to this research have often considerably hybrid identities: for example, as the first actor of Chinese nationality to study at the Royal Academy of Dramatic Art, whose subsequent career has repeatedly crossed continents, Tsai Chin is included in the database partly because her identity usefully raises questions concerning the definitions of Britishness that may underpin the notion of 'British Chineseness'. The presence of many other actors highlights the 
non-monolithic complexity of the notion of Chineseness: Issues of postcolonial cultural identity affect actors such as Tony Then and Pik-Sen Lim who were born in the then South East Asian colonies (respectively, Singapore and Malaysia). Their Chinese identity is thus inevitably differently informed to that of biracial actors such as Paul Courtenay Hyu and UK-born actors such as Gemma Chan. With my research not intending to police "the border: the boundary between "Chinese" and "nonChinese"' (Ang 2001: 85), but instead to engage with the 'fuzziness of the identity line, the fundamental uncertainty' (Ang 2001: 88) concerning definitions of Chineseness, the database has broadly tended towards inclusivity. This is especially important because my research precisely wants to avoid re-producing the marginalisation of the actors in question within the popular imagination.

Furthermore, what my discussion will demonstrate is that, the particularities and differences of their identities notwithstanding, a major commonality of experience for these actors is that the complexity of British Chinese identity is usually managed and erased through restrictive industrial practices and a representational ordering process (Dyer 2002). British television drama has frequently ascribed to them a notion of Chineseness that is not the 'open signifier' Ang (2001: 35) envisions, but one reduced to corporeal difference, rendering them a homogenous Other ultimately defined by their (flattened) Chineseness. The database brings together these diverse actors in order to begin to carve out a space for considering their lived experience, and to take account of the opportunities that have been available and/or lacking for British Chinese actors within the increasingly precarious working conditions of the British creative industries. In doing so, my work 
is aligned with that by Chow and Ang, whose anti-essentialist approaches to Chineseness resonate with the argument observed by Stuart Hall that 'the fact that "race" is not a valid scientific category [does not] "in any way [undermine] its symbolic and social effectuality"' (2005: 301).

\section{Dominant Representational Patterns}

The first point to note is that the commonly perceived long-standing absence of British Chinese identities is positively challenged by the presence of a wider range of British Chinese actors working in British television drama than is commonly acknowledged or remembered within the popular imagination. Familiar assumptions that relevant roles have been played by the same handful of actors, headed by the near inescapable Burt Kwouk, need to be revised in light of the fact that actors such as Jacqui Chan, Daphne Cheung, Paul Courtenay Hyu, Andy Ho, Arnold Lee, Pui Fan Lee, Robert Lee, Pik-Sen Lim, Barbara Yu Ling, Fiesta Mei Ling, Elizabeth Tan, Tony Then and Vincent Wong, have found notable employment in British television drama following the establishment of television as a mass medium in the 1950s. It is important that this range is noted, otherwise one risks neglecting and erasing the presence and creative work of actors such as those named above and their peers. ${ }^{4}$

Apart from the positively surprising scope of field, what has not been surprising to find is that there has been a limited number of more high-profile British Chinese actors. Headed by Burt Kwouk, these would include David Yip, Sarah Lam, Benedict Wong and more recently Gemma Chan. This is echoed across the Atlantic, 
where the stardom of Bruce Lee crowns a (proportionally larger) group of more prominent Chinese American actors working in television, including Rosalind Chao, Lucy Liu, Richard Loo, Keye Luke, Beulah Quo, Victor Sen Yung, Ming-Na Wen, B. D. Wong, Russell Wong and (to some extent) Joan Chen and Anna May Wong. British Chinese actors appear usually in minor roles, often playing one-off characters, in ways that transatlantically resonate with Dorothy B. Jones' (1955) pioneering study of Asian stock characters, including the role of waiter.

There is evidence of role segregation and major/minor role stratification. Here, I draw on Eugene Franklin Wong's (1978) important work, which argued that the US film industry was marked by these practices, whereby white actors could portray non-whites, but not vice versa; and that, the larger a role was, the more likely it was that a white actor would be cast. This holds true for British television drama, in that if a role is not specifically written for a (British) Chinese character, it is still today more likely to go to a white actor; British Chinese actors tend to get cast for (British) Chinese roles, less so for ethnically unmarked roles. The actor's British Chineseness is often an important, if not a defining feature, of the role he/she gets cast in - and with sensitive portrayals that engage meaningfully with the lived experience of British Chinese identity being noticeably sparse, this ethnic marking (as my discussion will explore further shortly) is predominately problematic. Here, Dan Li's 2013 appearance in Doctor Who (BBC1 1963-1989, 2005-present) is a rare instance, in that his British Chineseness is neither singled out nor made an issue within the episode. His character's name, Alexei, furthermore hints at a complex ethnic identity and suggests that the role was not specifically written for a British 
Chinese actor. Something ostensibly so simple, however, as the casting of an actor deemed suitable for a dramatic role remains regrettably elusive for British Chinese actors, as does switching between roles that are, and those that are not, marked by ethnic difference.

As a result, to date, the number of long-running appearances by British Chinese actors as regular/recurring characters are still limited, both in terms of number and time span: Burt Kwouk starred in BBC1 sitcom Last of the Summer Wine (1973-2010) from 2002 until 2010, Sarah Lam in BBC1 medical drama Angels (19751983) from 1981 until 1982, Andy Ho in BBC1 sitcom It Ain't Half Hot Mum (19741981) from October 1980 until August 1981, Pik-Sen Lim appeared in 27 out of a total of 42 episodes of Mind Your Language (ITV 1977-1982) and Kae Alexander has been in all three seasons of sitcom Bad Education (BBC3 2012-2014). Even in longrunning British soaps, there has been little space (or rather, time) for British Chinese actors: the longest stints here have chiefly revolved around those of David Yip and Sarah Lam as a married couple in Brookside (C4 1982-2003) for just over six months in 1989, Elizabeth Tan's role in Coronation Street (ITV 1960-present) from February until June 2011, and Jing Lusi in medical soap Holby City (BBC1 1999-present) from March 2012 until April 2013. Add to this the already mentioned The Chinese Detective (featuring David Yip) and children's series Spirit Warriors (whose cast included Jessica Henwick, Burt Kwouk, David Yip and Benedict Wong), and it is evident that lasting, high-profile roles have been scarce for British Chinese actors. ${ }^{5}$ 
This marginality clearly contributes to the perceived absence of British Chinese identities on screen, a perception that needs to be challenged by paying attention to the range of actors who have found employment in British drama. It may be useful to think of the (lack of) presence of British Chinese identities within the popular imagination in Britain via the visual metaphor of an iceberg floating in the sea: if one imagines British Chinese on-screen identities in this way, the limited number of better known actors such as Burt Kwouk and David Yip constitutes the proverbial tip, receiving (at least some) attention and recognition, as well as having to contend with the burden of representation. As Jonathan Gray remarks, where television provides little representation, 'those few characters that do exist become densely loaded with expectation and representational weight.' (2008: 111) The majority of British Chinese actors have remained a very real, but unattended presence below the water line, still awaiting more high-profile casting and inclusion in the popular imagination.

With the casting of British Chinese actors for British drama being predominately sporadic, their presence, when it does occur, is accompanied by a marking of ethnic difference on a number of levels. Firstly, where such an actor has appeared as a one-off character in a programme running for several episodes and/or seasons, the title of the episode in question has, at times, made reference to (a stereotypically limited range of) signifiers of Chineseness. For example, in his long career, Burt Kwouk appeared in episodes titled 'The Sinister Man', 'The Sign of the Claw', 'Take Away', 'All the Tea in China', 'The Peking Gun' and 'A Dragon by Any Other Name'. This practice possibly reached its nadir with 'Dim Sums', the painfully 
titled episode of ITV series King \& Castle (1986-1988) that featured David Yip. Across decades and genres, the appearance of a British Chinese presence has been extratextually framed in such a way that positions it and draws attention to it as Other and an issue, before any such presence actually took place on screen; and it is only in roughly the last two decades that this tendency has receded.

Secondly, a marking of ethnic difference has been more insistently detectible within British television drama's history at the level of role and character name. The choices made here reveal telling detail, such as those instances when British Chinese actors, playing roles that are not, as such, British Chinese, have been subject to what Kent A. Ono and Vincent N. Pham (2009) have termed 'implicit yellowface. ${ }^{6}$ This includes those occurrences where actors have been cast along strongly homogenising lines as 'generic Asians', such as Arnold Lee in ITV crime series Dempsey and Makepeace (1985-1986; the credits list him as 'Oriental hood') and the fairly numerous occasions where the casting transcends ethnic boundaries. Examples of the latter case, which can also be readily found within US television, ${ }^{7}$ include Burt Kwouk's recurring role as Japanese Captain Yamauchi in BBC1 drama series Tenko (1980-1984) and more recently, Dan Li's appearance as Mr. Watanabe in Secret Diary of a Call Girl (ITV2 2007-2011). Moreover, actors such as Arnold Lee were also cast on numerous occasions in only marginally less non-descript parts, including 'Chinese manager', 'Old Chinese Man' and 'Chinaman'. This fairly common practice of crudely defining and reducing roles for British Chinese actors by and to ethnic difference broadly subsided within British television drama during the 1980s, although it is still 
present on occasion: for example, Dan Li has appeared as 'Chinese Man' in BBC1 drama The Driver (2014), despite having a speaking part.

The use of crude, non-individuated, literally nameless character credits such as 'Chinese Man' was, for the most part, eventually replaced by the deployment of actual character names, only these have been noticeably generic, such as Lee, Ling, Chen, Cheng and Ching. Ling, for example, has been used as both a first name and surname for characters played by, amongst others, Burt Kwouk, Pik-Sen Lim and Robert Lee, on numerous occasions. Displaying a limited imagination (if not lack of effort) by the relevant production teams, such designations are less a name for (individual) dramatic characters and more a placeholder - not dissimilar to an ethnic version of 'Joe Bloggs' - implying, through their frequent use, a sense of typicality, commonality and fungibility, and to some extent transferring those qualities onto the characters they designate.

The linguistic choices for character names in themselves can, of course, only yield a limited amount of information, and it is necessary to test out in what ways these naming conventions work in tandem with on-screen stereotypes and/or whether tensions are placed on the generic, clichéd and homogenised/homogenising names via narrative and/or performance choices. For example, the 2003 episode 'Ancient Eastern Wisdom - An Introduction' of Last of the Summer Wine contains this jokey exchange about the name of Burt Kwouk's character:

Clegg (Peter Sallis): [...] but how come you've got a name like Entwistle? 
Entwistle (Kwouk): I changed my name, didn't I. From Maclntyre. I was forever being mistaken for a Scot.

Here, the reaction shots and Kwouk's matter-of-fact delivery underscore a playful reversal of assumptions and expectations concerning the (so often, apparently inevitable) linguistic identity of a character of Chinese descent. However, while (to some extent) an improvement on the nameless parts that had been in currency until the 1980s, the clichéd ethnic names, present since the early decades of British television, indicate an unproductive, if not reductive, fixedness on ethnic difference. Inasmuch as they link 'to some notion of normativized, authentic standard of Asianness' (Ono and Pham 2009: 54), they need to be understood as a type of implicit yellowface.

Thirdly, the marking of ethnic difference is often played out at a textual level through the deployment of stereotypes, which as Hall (1997) established, work to reduce, essentialise, naturalise and fix difference. British Chinese actors who find employment in British television frequently find themselves within representations that, as already noted, draw on long-standing Asian stock characters and tropes; and the use of stereotypes and reductive tropes is predominately devoid of a critical intention that seeks to interrogate and/or subvert these. Here, the deployment of stereotyping involving notions of criminality is striking - British Chinese actors have been cast for a limited range of roles: too often, that of the criminal. This is linked to a historical tendency for such actors to get cast in programmes within the fantasy, action and crime genres, as well as the long-standing yellow peril discourse running 
through Western cultural media. This representational discourse is embodied in the iconic figure of Fu Manchu, the arch villain of the Sax Rohmer novels, 'cruel, vicious, and a throwback to Genghis Khan.' (Xing 2009: 116) It is noticeably present in 1960s action shows like The Avengers (ITV 1961-1969), The Saint (ITV 1962-1969) and The Prisoner (ITV 1967-1968), which featured appearances by actors including Jacqui Chan, Burt Kwouk, Robert Lee and Barbara Yu Ling. James Chapman has pertinently argued that the representations within these 1960s programmes need to be understood as informed by both "the old idea of the "yellow peril" that has pervaded western popular culture, in which the oriental races [sic] are depicted as a villainous, inscrutable "other" which intends to subjugate white, European, Christian civilisation' (2006: 123), as well as within their contemporary context of the Cold War, China's Cultural Revolution and emergent use of nuclear weapons. In the 1960s, China was seen as an ideological and geopolitical threat to the West, and this anxiety informed these programmes whose narratives were often concerned with Chinese ambitions and conspiracies for power.

However, even though the end of the Cold War saw representations within British television drama become defused, there is a long-term pattern in British television drama that has seen British Chinese actors play roles connected to criminality, in programmes from a range of genres, which rarely explore the socioeconomic contexts of the criminal activity. This holds true for the contemporary period, which has seen an influx of British Chinese actors in British television drama, across a range of genres: soap Coronation Street, sitcoms Last of the Summer Wine and Bad Education, the acclaimed Sherlock, children's series Spirit Warriors and 
gritty drama Top Boy (C4 2011-2013; Netflix 2019-) have recently featured British Chinese actors in more prominent roles. Here, in programmes as varied as Sherlock, Top Boy and Coronation Street, the characters in question have been involved in criminal activity of different kinds. This influx and the sustained connection to criminality are linked, respectively, to the presence of British Chinese individuals in factual television and entertainment culture (e.g. Alexa Chung, Gok Wan) and the rise of China as a global economic super power. Further informed by Hong Kong action cinema and actions of the Chinese regime, the sustained connection to criminality in British television drama has become a self-sustaining trope; one that has, I would suggest, become so self-evident that, ironically (given the noted cultural invisibility of British Chinese identities), it has acquired an invisibility of its own.

\section{Case Study: Sherlock and 'The Blind Banker'}

Having identified some of the major representational tendencies in British television drama, this article now moves to Sherlock, and specifically 'The Blind Banker', to provide more specific texture to these broader patterns. In this first season episode of the contemporary re-envisioning of Arthur Conan Doyle's fictional detective cocreated by Steven Moffat and Mark Gatiss, Holmes (Benedict Cumberbatch) and Watson (Martin Freeman) uncover a Chinese crime syndicate. A relatively large number of British Chinese actors are cast in this episode, including, as per the end

credits, Gemma Chan as Soo Lin Yao, Sarah Lam as 'Opera Singer' and Jacqui Chan as 'Shopkeeper'. The episode begins with Soo Lin at her work as a ceramic expert at a London museum, performing a tea ceremony for visitors. Whilst this offers a 
somewhat exoticised framing according to a stereotyped set of cultural expectations, it hints at the character's educational and professional achievements and the common perception of the British Chinese as a 'model minority'.

The representational 'model minority' stereotype has become fairly prevalent on US television: the persistence of yellow peril discourse in US media traced by Ono and Pham (2009) has sat side by side a move to casting Asian American actors as high-achieving professionals (especially in medicine and law) in programmes such as Ally McBeal (Fox 1997-2002) and Law \& Order: Special Victims Unit (NBC 1999-present). Problematic as this stereotype is, ${ }^{8}$ it is notable in British drama for being significantly less present. Writer and director Jo Ho has in an interview called for an overdue shift in this dominant representational stereotype: 'And for East Asians like me, please, please do away with the criminal storylines there really are more of us in this country who are doctors, nurses, lawyers and accountants than there are triads, illegal immigrants and prostitutes.' (cited in Hussein 2011) Despite its potentially promising beginning, 'The Blind Banker' proceeds to ignore Ho's call, revealing that Soo Lin was a member of the 'Black Lotus Tong,' run by the Opera Singer under the guise of a travelling circus. On the rare occasion that British Chinese actors find employment on Sherlock, this is intertwined with the presence of exoticising stereotypes - in addition to the tea ceremony, there are the circus performers' uncanny tricks, while shots of Chinatown emphasise its Otherness through a dense compositional arrangement of red lanterns - and that most troubling representational pattern, criminality. 
So, stereotypes are in no short supply. Richard Dyer has noted:

a particularly interesting potential use of stereotypes, in which the character is constructed, at the level of dress, performance, etc., as a stereotype but is deliberately given a narrative function that is not implicit in the stereotype, thus throwing into question the assumptions signaled by the stereotypical iconography. (2002: 15)

Might such a potential critical project be at stake here? Certainly, a degree of performativity is detectable: the tea ceremony, the escapology/acrobatic circus acts and the 'Lucky Cat' shop in Chinatown are all staged in such a way as to emphasise a performance of Chineseness taking place for visitors. Long shots repeatedly highlight the museum/circus visitors witnessing skillful acts by costumed performers; and the scaffolding next to and strong patterning of stock display within the shop acknowledge its constructedness. So, a performative quality inflects these exoticising stereotypes. Moreover, they need to be understood in the context of the discourses of heritage and tourism that pervade Sherlock, running alongside similarly stereotypical, export-friendly notions of Britishness in this co-production aiming for success on the global television market. And, of course, the link to criminality makes sense within the context of Sherlock's genre. However, this plotline is not brought in directly from the literary source material. So, the link between (British) Chinese culture and criminality is a deliberate choice, as is the decision to cut the shooting script's reference to Soo Lin's parents having died in the 1989 Tiananmen Square protests - such socio-political concerns were presumably found to be too jarring for the discourses of heritage and exportability. ${ }^{9}$ 
However, what I find more revealing still are choices pertaining to issues of tone, a concept which, as Douglas Pye has established, concerns 'the ways in which the film addresses its spectator and implicitly invites us to understand its attitude to its material and the stylistic register it employs.' (2007: 7) While the programme overall is noted for a contemporary take and knowing commentary on the source material's Victorian sensibility and its own representational politics (e.g. the playful references to the homosexual subtext between Holmes and Watson), neither is observable for the reductive representation of (British) Chinese culture. It seems that Sherlock Holmes can use SMS messaging and GPS tracking, but (British) Chinese culture here does not escape the sinister villains of the 'Black Lotus Tong,' and this clichéd yellow peril receives no ironic commentary of any kind. (Even the unnecessarily overelaborate scenario for the final showdown, which involves the villains using a big crossbow in a tunnel in order to extract information out of Watson, is presented in a serious frame.) Such ironic self-reflexivity would not necessarily render the clichés acceptable, but is noticeable for its absence here. The self-sustaining trope concerning criminality noted earlier has in Sherlock become so self-evident and invisible to the production team that it warrants no self-reflexive engagement. In this, the production team is joined by the British press, which took virtually no issue with these representational politics, concentrating instead on the deployment of storytelling and style ${ }^{10}$ in the episode (whose title, ironically enough, refers to blindness).

With the presence of stereotypes thus marking their ethnic difference, the characters with Chinese descent in Sherlock receive little time and space for 
characterisation, especially in comparison to other short-lived characters such as Watson's love interest Sarah (Zoe Telford), who is also introduced in this episode. Gemma Chan's, Sarah Lam's and Jacqui Chan's characters lack individuation reflected in the credits of 'Opera Singer' and 'Shopkeeper' for the latter two - and further actors, including the one who plays Soo Lin's brother Zhi Zhu, receive no credit, despite the demonstration of some specialist acrobatic skills that would warrant inclusion. (This is perhaps because none of the male actors of East Asian descent gets to speak a line of on-screen dialogue in the 90-minute long episode.) Chan's and Lam's characters are largely reduced to the Lotus Blossom/Dragon Lady binary (see Tajima 1989): described in the episode's shooting script as a 'fragile little doll,' the former displays a lack of agency and suffering submissiveness that are remarkable for an ex-drug smuggler who has successfully built a new life in another country. The latter is the inverse; strong, ruthless and with an evil smirk. This is no criticism of the actors, who are placed under firm limitations by the material; and with the violent deaths of both female characters and Zhi Zhu, none of them receive character development. With a closing scene dedicated to Soo Lin's memory cut from Steve Thompson's shooting script, Sherlock exhibits a very finite amount of interest in these characters.

Marked by a narrowness of identity that re-produces their Othering, the presence of these actors functions in subservience to the demands of plot and genre and as an auxiliary to the (lead) roles played by white actors. In this, Sherlock differs from the contemporary US television adaptation of Sherlock Holmes, Elementary (CBS 2012-present), which, with Lucy Liu as Watson, represents a development of 
the historical tendency that 'Asian Americans on network television programs exist primarily for the convenience and benefit of the Euro-American lead players.' (Hamamoto 1994: 206) Sherlock is part of the wider, extant tendency that British Chinese actors have had few opportunities to play well-rounded characters on British television, having too often to contend with featureless, interchangeable parts. Here, Jun Xing's argument concerning Hollywood, can and must be crossapplied:

In on-screen portrayals, white actors and actresses have been depicted as representing the entire spectrum of social and human types, whereas the professional horizons for Asian actors are very limited. [...] This system of stereotypical delimitations has successfully prevented dimensional development and aesthetic continuity in the creation of Asian characters on the screen. (2009: 137)

This lack of differentiation is a considerable representational problem, not only at the level of individual character, but also in wider social terms. Because, as Sherlock exemplifies, the work of such actors has been locked within narrow parameters, there has been very little sense of the concept of a British Chinese community, let alone recognition of the heterogeneous nature of the very notion of a British Chinese community, in British television drama. This problem was set up in the early decades of British programming, when British Chinese actors were cast in marginal, Chinese (as opposed to British Chinese) roles, such as 'Chinese villain', in telefantasy genre programming less concerned with representing a recognisable social world. This established their presence as that of 'perpetual foreigner' (see Wu 
2002), implying that they lack a rightful place and sense of belonging in Britain, as part of a long Western tradition, considered in Edward Said's seminal critique of Orientalism (2003 [1978]), whereby the 'Orient' is discursively constructed as distinct from the 'Occident' and continually separate.

In Sherlock, Soo Lin lives above the 'Lucky Cat' shop in Chinatown, and goes into hiding at the museum. When Holmes and Watson are looking for her, they break into her flat, with no attempt to check in with neighbours (despite having earlier in the episode enlisted a neighbour's help to break into a white British banker/smuggler's apartment). There is no sign of a community that may offer help; on the contrary, Soo Lin comments that 'in a small community like ours, they [the Tong] are never very far away.' So, the exoticised Chinatown is linked to danger, not support; and years after emigrating, Soo Lin remains a perpetual foreigner, and a disconnected, atomised perpetual foreigner at that. In this, she is representative of British Chinese representations within British television drama, which has thus far not made sufficient use of its long-form potential to establish British Chinese identity as a more recognised part of British social life, belonging and not perpetually foreign. This is a crucial undertaking, for, to transnationally adapt Darrell Hamamoto's argument, the socio-cultural construction of British Chinese Otherness is a precondition 'for their cultural marginalization, political impotence, and psychic alienation from mainstream [British] life.' (1994: 5)

The issues with Sherlock's politics of representation outlined above are troublingly representative of wider tendencies in British television drama, but even 
more concerning because Sherlock is a flagship drama for the BBC, with a strong presence in public discourses concerning quality television and the $\mathrm{BBC}^{\prime} \mathrm{s}$ remit as a public service broadcaster. Its 2007-2016 Royal Charter states that one of the public purposes of the BBC concerns 'representing the UK, its nations, regions and communities;' (DCMS 2006: 2) and yet this episode articulates, if not typifies, two of the key dogmas of Orientalism identified by Said (2003 [1978]). He pointed out Orientalism's 'absolute and systematic difference between the West, which is rational, developed, humane, superior, and the Orient, which is aberrant, undeveloped, inferior.' (Said 2003 [1978]: 300) Sherlock pits Holmes' towering intellect and digital proficiency, Watson's empathy and their witty repartee against the sororicidal, arbalest-lugging and ominously silent Tong. Said further argued that 'the Orient is at bottom something either to be feared (the Yellow Peril, the Mongol hordes, the brown dominions) or to be controlled' (2003 [1978]: 301); and the perilous Tong are mastered in 'The Blind Banker' by white Western masculinity (Holmes and Watson, as well as an off-screen Moriarty, who kills the Opera Singer in the closing moments). In an age of deregulated, commercially driven broadcasting, Sherlock here displays a preoccupation with developing a distinct visual brand that will be globally exportable, and not with sensitivity towards representational matters, the UK's diverse communities or mindfully engaging with the stylishly rendered and globally recognisable stereotypes it employs. ${ }^{11}$ Co-produced with WGBH Boston, this preoccupation has helped Sherlock become one of the BBC's global superbrands, but its achievements regarding the public service responsibility to educate and inform as well as its intention to construct 'a deep sense of national consciousness and consensus' (Creeber 2004: 29) are here questionable. 
Reflective of both the wider patterns of British Chinese representations in British television drama and the current neo-liberal context within which the BBC is located, the issues with Sherlock's politics of representation point to the acute need for more programmes that counter the dominant representational narrowness that (at best) risks homogenising and essentialising the lived experience of British Chinese identity. Here, The Chinese Detective from the early 1980s has for too long remained a positive exception, with its central character John Ho (David Yip) being invested with a developed sense of background, a complex relationship with his father and with limited talent for playing the piano. The latter might seem inconsequential, but such touches of characterisation help afford humanity to a role; something which British Chinese actors have been largely unable to experience. Moreover, John Ho was placed within a dramatically significant and complex community that was not exclusively peopled by British Chinese characters, signaling an understanding of British Chinese identity as Chinese and British, as belonging and not perpetually foreign. More such programmes would ease the burden of representation on The Chinese Detective (which was, it is worth recalling, influenced by the Charlie Chan detective films of the 1930s) and help provide more nuanced television engagement with British Chinese identity.

The issues with Sherlock's politics of representation also point to the need for more British Chinese self-representation. With Jo Ho credited as the first person of Chinese descent to have created a drama series (Spirit Warriors) for British television, the programming in which British Chinese actors have appeared has been 
overwhelmingly written, produced and directed by white British personnel. Of course, the latter does not inevitably produce inherently flawed, and selfrepresentation does not necessarily result in unproblematically progressive (or authentic), representational politics. This is attested, respectively, by lan Kennedy Martin's The Chinese Detective and the widespread criticism that has been levelled at Chinese Burn (BBC3 2017), a British sitcom pilot written by and starring Yennis Cheung and Shin-Fei Chen, for perpetuating negative stereotypes (especially concerning its representation of Chinese masculinity). However, more nuanced expression of and a wider range of perspectives on British Chinese culture must surely involve a greater degree of self-representation, which US television has been slowly shifting towards with recent programmes such as Black-ish (ABC 2014present), Master of None (Netflix 2015-present) and Atlanta (FX 2016-present). Certainly, more self-representation would help to avoid repeats of the displeasure expressed by viewers online at the sight of the use of origami lotuses in 'The Blind Banker', which was understandably not received as a reflection of the fact that paper folding arts are not exclusive to Japan, but as cultural ignorance and dismissiveness.

\section{Conclusion}

More needs to be said about the representation of British Chinese identities both within Sherlock and British television drama more broadly, especially concerning gender, mysteriousness, humour and periodisation. My discussion has traced some temporal developments, mostly hinged around the 1980s, which saw a move towards deregulation of broadcasting, the arrival of Channel 4, whose remit included 
catering for minority interests, and a growing awareness of issues concerning cultural diversity in British television. The latter was indebted to the work of (mostly African Caribbean- and South Asian-focused) advocacy groups and organizations such as the Commission for Racial Equality and the high-profile debates about diversity surrounding the Annan report (1977). Limited space means that this article will conclude with briefly reflecting on the contemporary moment, which has seen an already noted influx of British Chinese actors in British television. This is accompanied by a noticeable push-pull: Dan Li plays Alexei in Doctor Who in 2013 and becomes a criminal 'Chinese man' in 2014 for The Driver. A fragile Lotus Blossom (who dies) in Sherlock in 2010, Gemma Chan explores her character's sexual attraction to women (and survives) in Dates (C4 2013). Both Coronation Street's Xin and Wok's (2016) Bruce work in Chinese takeaways, but Xin became involved in criminal activity when she married another character to get a British passport, in a plotline tapping into illegal immigrant discourses (see Thorpe 2011); while the sitcom pilot created by Bruce Chong and Chris Chung has received praise for its nuanced handling of representational issues.

This push-pull sits in a wider trajectory of contradictory constructions marking East Asian representations, including the yellow peril/model minority, Fu Manchu/Charlie Chan and Lotus Blossom/Dragon Lady binaries. Peter X Feng's argument that such 'contradictions in representations of Asian Americans [...] express a crisis in the definition of what it means to be American' (2002: 1) holds resonance for the British context: important socio-cultural concerns are being worked through, and with some urgency, and it will be significant to follow how 
these developments take further shape and what kinds of relationships they form with representational patterns from the past. It is worth here recalling Karen Shimakawa's point about theatre performance, namely that: 'Asian American performers never walk onto an empty stage; [...] that space is always already densely populated with phantasms of orientalness through and against which an Asian American performer must struggle to be seen.' (2002: 17) Certainly, this applies to British Chinese actors, who have been struggling to be seen.

This struggle has received supported in recent years from increasing discursive attention being paid to issues concerning diversity and inclusion. With advocacy pressure by, amongst others, Equity, the Triforce Creative Network, Lenny Henry, Riz Ahmed, as well as the British East Asian Artists pressure group, sociopolitical and -cultural debates about Black, Asian and Minority Ethnic (BAME) representation have gained unprecedented visibility, and a number of recent institutional/industrial initiatives aim to facilitate on- and off-screen minority identity representation. Such advocacy work and the nurturing of on- and off-screen talent from backgrounds that are not white and/or (otherwise) privileged are undoubtedly important, especially given that the BBC (after several initiatives to address minority inclusion) was called 'hideously white' by its then-Director General Greg Dyke in 2001, and the increasing commercial pressures on British broadcasting.

It remains to be seen whether there will be a sustained move away from cultural invisibility, marginalisation, stereotyping and Othering, and towards programming marked by positive visibility - namely, roles that are ethnically 
unmarked (in the sense that a role played by an actor who is not white is not inevitably defined by this aspect of the actor's identity) and those that address issues of representation with intersectional sensitivity and subtlety. I am wary of invoking the USA as a straightforwardly positive representational role model for British television, given its long (and continuing) history of problematic approaches to representation; ${ }^{12}$ but the age of 'peak TV' has at least created a space for programmes such as Fresh Off the Boat (ABC 2015-present) to receive mainstream exposure. In the UK, Chinese Burn has stayed at the level of pilot for the relative niche platform $\mathrm{BBC}$, and the crowd-funded Wok pilot is yet to be broadcast on television.

The distinctions and nuances this article has pointed to suggest the value of a closer dialogue between the creative industry and academic research. Such nuance is important for British Chinese identities, both because nuance has been absent from most on-screen representations and because the specific contexts of individual minority groups matter. For example, the high-profile achieved by contemporary campaigning for more on- and off-screen diversity is significant for British Chinese campaigners, who, feeling that theirs has been 'lagging behind other ethnic groups' (Baluch 2009), have had to contend with the fact that they have long been perceived as an invisible and/or silent minority. The research that informs this article will continue with its two-pronged intention: firstly, by uncovering what has been marginalised, to produce a rich textual history of British television drama; and secondly, to engender and support further debates about British Chinese identities within British culture. Signposting important avenues for further analysis, this article 
has made a start to pull British Chinese television representations into the field of critical vision and open them up for more sustained debate as an important part of television culture and Britain's wider cultural heritage. 
Ang, len (2001), On Not Speaking Chinese: Living Between Asia and the West, London; New York: Routledge.

Baluch, Lalayn (2009), 'British East Asian artists lambast "racist" British theatre for lack of acting roles', The Stage, 9 June, available at http://www.thestage.co.uk/news/2009/06/british-east-asian-artists-lambast-racistbritish-theatre-for-lack-of-acting-roles/.

Benton, Gregor and Gomez, Edmund (2008), The Chinese in Britain, 1800-Present: Economy, Transnationalism, Identity, Houndmills, Basingstoke: Palgrave.

Chapman, James (2006), Saints and Avengers: British Adventure Series of the 1960s, London; New York: I. B. Tauris.

Chen, Anna (2010), 'Sherlock and wily orientals: Blind Banker, Episode 2 review', Madam Miaow Says, 1 August, available at http://madammiaow.blogspot.com/2010/08/sherlock-and-wily-orientals-bbcstuck.html.

Chow, Rey (1998), 'Introduction: On Chineseness as a Theoretical Problem', boundary 2, 25: 3, pp.1-24.

Creeber, Glen (2004), “'Hideously White”: British Television, Glocalization, and National Identity', Television \& New Media, 5: 1, pp. 27-39.

Department for Culture, Media and Sport (DCMS; 2006), Broadcasting: Copy of Royal Charter for the continuance of the British Broadcasting Corporation, London: The Stationery Office.

Dyer, Richard (2002), 'The Role of Stereotypes' in The Matter of Images: Essays on Representation, 2nd edn, London; New York: Routledge, pp.11-18.

Feng, Peter X (2002), 'Introduction' in Feng, Peter X (ed.) Screening Asian Americans (New Jersey; London: Rutgers University Press), pp. 1-18.

Gray, Herman (2000), 'Black Representation in the Post Network, Post Civil Rights World of Global Media' in Cottle, Simon (ed.), Ethnic Minorities and the Media: Changing Cultural Boundaries, Buckingham; Philadelphia: Open University Press, pp. 118-130.

Gray, Jonathan (2008), Television Entertainment, New York; London: Routledge.

Greco Larson, Stephanie (2006), Media \& Minorities: The Politics of Race in News and Entertainment, Lanham: Rowman \& Littlefield Publishers. 
Hall, Stuart (1995), 'The Whites of Their Eyes: Racist Ideologies and the Media', in Dines, Gail and Humez, Jean M. (eds.), Gender, Race and Class in Media: A TextReader, London: Sage Publications, pp. 18-22.

Hall, Stuart (1997), 'The Spectacle of the "Other"' in Hall, Stuart (ed.), Representation: Cultural Representations and Signifying Practices, London: Sage Publications, pp. 225-279.

Hall, Stuart (2005), 'For Allon White: metaphors of transformation' in Morley, David and Chen, Kuan-Hsing (eds.), Stuart Hall: Critical Dialogues in Cultural Studies, London; New York: Routledge, pp. 286-305.

Hamamoto, Darrell Y. (1994), Monitored Peril: Asian Americans and the Politics of TV Representation, Minneapolis: University of Minnesota Press.

Hussein, Jamil (2011), 'Interview with Jo Ho, creator of BBC drama series, "Spirit Warriors"', The TV Collective, 14 November, available at http://www.thetvcollective.org/2011/11/14/5156/.

Jones, Dorothy B. (1955), The Portrayal of China and India on the American Screen, 1896-1955, Cambridge, Massachusetts: Center for International Studies.

Kim, L. S. (2004), 'Be The One That You Want: Asian Americans in Television Culture, Onscreen and Beyond', Amerasia Journal, 30: 1, pp. 125-146.

Malik, Sarita (2001), Representing Black Britain: Black and Asian Images on Television, London: Sage.

Malik, Sarita and Newton, Darrell M. (eds.) (2017), Adjusting the Contrast: British Television and Constructs of Race, Manchester: Manchester University Press.

Marchetti, Gina (1993), Romance and the "Yellow Peril": Race, Sex, and Discursive Strategies in Hollywood Fiction, Los Angeles: University of California Press.

Office for National Statistics (ONS; 2009), Population Estimates by Ethnic Group: 2001 to 2007 Commentary, London: Office for National Statistics.

Ono, Kent A. and Pham, Vincent N. (2009), Asian Americans and the Media, Malden: Polity Press.

Penny, Laurie (2010), 'I'm tired of stories about clever white men and how special they are', New Statesman Blog, 3 August, available at:

https://www.newstatesman.com/blogs/laurie-penny/2010/08/sherlock-holmesbritish.

Poore, Benjamin (2017), Sherlock Holmes from Screen to Stage: Post-Millennial Adaptations in British Theatre, London: Palgrave. 
Pye, Douglas (2007), 'Movies and Tone', in Gibbs, John and Pye, Douglas (eds.), Close-Up 02, London: Wallflower Press, pp. 1-80.

Pratten, Nyima (2012), 'The British Chinese community and the UK media', The Independent Blog, 6 August, available at

http://blogs.independent.co.uk/2012/08/06/the-british-chinese-community-andthe-uk-media/.

Rutherford, Jonathan (1990), 'The Third Space: Interview with Homi Bhabha', in Rutherford, Jonathan (ed.) Identity: Community, Culture, Difference, London: Lawrence and Wishart, pp. 207-221.

Said, Edward W. (2003 [1978]), Orientalism: Western Conceptions of the Orient, London: Penguin Books.

Shimakawa, Karen (2002), National Abjection: The Asian American Body Onstage, Durham, NC: Duke University Press.

Tajima, Renee E. (1989), 'Lotus Blossoms Don't Bleed: Images of Asian Women' in Asian Women United of California (eds.), Making Waves: An Anthology of Writings By and About Asian American Women, Boston: Beacon Press, pp. 308-317.

Thorpe, Ashley (2011), 'Following the Arts Councils cuts, the fight to represent British Chinese communities has just got harder', Screens and Stages blog post, 6 April, available at https://fttreading.wordpress.com/2011/04/06/following-the-artscouncils-cuts-the-fight-to-represent-british-chinese-communities-has-just-gotharder/.

Walton, John K. (2004), 'Introduction', in Caunce, Stephen et al (eds.), Relocating Britishness, Manchester: Manchester University Press, pp. 1-16.

Wollaston, Sam. (2010), 'Last night's TV: The fabulous Baker Street boys just get better and better - and scarier, too', The Guardian, 2 August, p. 25.

Wong, Eugene Franklin (1978), On Visual Media Racism: Asians in the American Motion Pictures, New York: Arno.

Wu, Frank (2002), Yellow: Race in America Beyond Black and White, New York: Basic Books.

Xing, Jun (2009), 'Cinematic Asian Representation in Hollywood', in Friedman, Jonathan C. (ed.), Performing Difference: Representations of "The Other" in Film and Theater, Lanham: University Press of America, pp. 113-143.

Yuen, Nancy Wang (2017), Reel Inequality: Hollywood Actors and Racism, New Brunswick, New Jersey; London: Rutgers University Press. 
${ }^{1}$ The latter can be found in, for example, journalistic commentary (e.g. Pratten 2012) and documentary/comedy series The Missing Chink (C4 2004).

${ }^{2}$ There are some parallels here with the USA, where, Stephanie Greco Larson observes, 'Asian Americans have been excluded from film and television roles.' (2006: 67)

${ }^{3}$ John K. Walton (2004) has noted the heterogeneity of British identity.

${ }^{4}$ How this presence sits vis-à-vis the cultural invisibility as perceived within British Chinese discourses is an interesting question beyond this article's scope.

${ }^{5}$ In the USA, they also proved elusive for then-future pop cultural icon Bruce Lee who, despite having starred in The Green Hornet (ABC 1966-1967) and having had involvement in the concept for Kung Fu (ABC 1972-1975), reportedly lost out on the main role in the latter to David Carradine 'because he looked "too Asian."' (Greco Larson 2006: 68)

${ }^{6}$ British television drama history also includes instances of explicit yellowface appearances, including that by John Bennett as villain Li H'sen Chiang in the 1977 Doctor Who episode 'The Talons of Weng-Chiang'.

${ }^{7}$ For example, Korean American comedian Margaret Cho's All-American Girl (ABC 1994-1995), the first US sitcom with an all-Asian American cast, 'came under critique for having more actors who were not Korean American than those who were.' (Ono and Pham 2009: 56)

${ }^{8}$ In the USA, model minority discourse denies the structural inequality and discrimination experienced by Asian Americans, politically pits them against other 
minority groups and undermines advocacy for social change, thus not challenging the dominant social order (see Marchetti 1993).

${ }^{9}$ Sherlock has achieved considerable popularity in China.

${ }^{10}$ A review for The Guardian commented that: 'Last week's opener was good; this one, written by Steve Thompson, is better. Crucially, it's scarier - with some proper creepy moments in a dark museum, and the ominous threat of ruthless Chinese gang culture hanging over the whole thing. The plot is more satisfying - clearer and more self-contained. [...] It's pacy, exciting and it looks brilliant.' (Wollaston 2010: 25) Laurie Penny (2010) and writer Anna Chen (2010) were welcome exceptions.

${ }^{11}$ Sherlock's politics of representation concerning gender and sexuality have come under fan, press and scholarly scrutiny. Benjamin Poore (2017) considers the figure of Holmes in relation to class, gender and race privilege.

12 US television has recently improved its representational track record, with acclaimed on-/off-screen diversity exemplified by Crazy Ex-Girlfriend (The CW 2015present) and Insecure (HBO 2016-present). However, a significant difference is generally to be drawn between network and non-network television, and successful individuals such as Shonda Rhimes and Donald Glover remain high-profile exceptions in a vastly bigger US television landscape. 